\title{
Recurrence of sickness absence due to common mental disorders
}

\author{
Petra C. Koopmans • Ute Bültmann • \\ Corné A. M. Roelen $\cdot$ Rob Hoedeman . \\ Jac J. L. van der Klink · Johan W. Groothoff
}

Received: 15 January 2010 / Accepted: 19 April 2010 / Published online: 7 May 2010

(C) The Author(s) 2010. This article is published with open access at Springerlink.com

\begin{abstract}
Purpose Common mental disorders (CMDs) are an important cause of work disability. Although CMDs are known to have high recurrence rates, little is known about the recurrence of sickness absence due to CMDs. This study examines the recurrence risk of sickness absence due to CMDs.

Methods A cohort of 9,904 employees with a sickness absence due to CMDs, working in the Dutch Post or Telecommunication company, was studied over a 7-year period. Recurrence was defined as the start of at least one new episode of sickness absence with CMDs after complete return to work for at least 28 days. The recurrence density (RD) of sickness absence with CMDs was calculated per 1,000 person-years.
\end{abstract}

Results Of the 9,904 employees with a first absence due to CMDs 1,925 (19\%) had a recurrence, $90 \%$ of recurrences occurred within 3 years. The RD of sickness absence due to CMDs was 84.5 employees per 1,000 person-years (95\% CI $=80.7-88.3$ ). The RD of sickness absence due to CMDs was similar in women and in men. In men, depressive symptoms were related to higher recurrence of sickness absence due to CMDs than distress symptoms and adjustment disorders. In women, no difference by diagnostic category was found.

Conclusions Employees with a previous episode of sickness absence with CMDs are at increased risk of recurrent sickness absence with CMDs. Relapse prevention consultations are recommended for a period of 3 years after return to work.

Keywords Recurrent sickness absence - Common mental disorders · Stress-related symptoms · Depressive symptoms $\cdot$ Anxiety symptoms

\section{Introduction}

Sickness absence due to mental disorders is a major public and occupational health problem, associated with many individual, social and economic implications (Mykletun et al. 2006; Bültmann et al. 2006, 2008; Lerner and Henke 2008; Eaton et al. 2008). In most western European countries, mental disorders are the second most frequent cause of sickness absence, after musculoskeletal disorders (Alexanderson and Norlund 2004; Vaez et al. 2007). The increase in sickness absence due to common mental disorders (CMDs), in particular depression, anxiety disorders, and stress-related disorders, is higher than for other disorders (Alexanderson and Norlund 2004; Vaez et al. 2007),

ArboNed Occupational Health Services Corporate Accounts, PO Box 85091, 3508 AB Utrecht, The Netherlands 
and symptoms of depression and anxiety have been shown to predict disability pension in Norway and Denmark (Mykletun et al. 2006; Bültmann et al. 2008). In the United Kingdom, sickness absence due to mental disorders is nowadays the major cause of sick leave, accounting for almost $40 \%$ of all sickness absence (Shiels et al. 2004).

Few studies have investigated characteristics of sickness absence due to mental disorders (Hensing and Wahlstrom 2004). The most consistent finding was that women were more frequently sick-listed due to mental disorders than men. However, even though mental disorders are more common among women, sickness absence seems to be longer among male employees with mental disorders than among female employees (Hensing et al. 2000; LaitinenKrispijn and Bijl 2000). Vaez et al. (2007) found that $65 \%$ of the employees with long-term sickness absence due to mental disorders had high levels of sickness absence in the three following years. Although the recurrence rate of mental disorders is assumed to be high (Mueller et al. 1999; Crown et al. 2002; Keller 2002; Yonkers et al. 2003; Robinson and Sahakian 2008), the recurrence of sickness absence due to CMDs has not yet been studied. Therefore, in this study we addressed the following research questions:

1. What is the recurrence of sickness absence due to CMDs, and the median time to recurrence?

2. Which determinants are related to the recurrence of sickness absence due to CMDs?

\section{Methods}

Study population and study design

This study was based on a cohort consisting of 9,904 employees who have had an episode of sickness absence due to a medically certified CMD. The cohort was drawn from a population of employees working in the Dutch Post and Telecommunication company in the period 2001-2007. The total population consisted of 137,172 employees $(62 \%$ men and $38 \%$ women). Approximately $70 \%$ of the employees worked in the Post company and 30\% in the Telecommunication company. Their main work tasks included sorting, transport and delivery of mail, post office activities and back-office, technical, sales, information technology, and executive tasks.

Data on sickness absence in the years 2001 through 2007 were collected retrospectively from the records of the ArboNed Occupational Health Services.

The Medical Ethics Committee of the University Medical Center in Groningen informed us that ethical approval was not required because the data were analyzed in retrospect at group level.

\section{Measurements}

\section{Sickness absence data}

ArboNed Occupational Health Services collects sickness absence data by automatic upload from the company's absence register, and sick-listed employees usually visit the occupational health physician for a medical certification of absence in the third week of absence. The occupational physicians classify mental disorders according to the Dutch Guidelines for Mental Disorders (Van der Klink and van Dijk 2003) based on the 10th International Classification of Diseases (ICD-10) as follows: distress symptoms (ICD-10 code R45), stress-related disorders (ICD-10 code F43 including acute stress reactions and adjustment disorders), depressive disorders (ICD-10 code F32), anxiety disorders (ICD-10 code F40 and F41) and other psychiatric disorders, such as psychoses, bipolar affective disorders, and disorders caused by psychoactive substances. Although distress symptoms (R45) are not a psychiatric code, we included it in our study because it is a frequently encountered CMD in the occupational health practice.

Sickness absence on the organizational level is computed as the number of calendar days of sickness absence in a year, adjusted for partial return to work divided by $365 \times$ mean number of person-years in that year. Adjustment for partial return to work means that when an employee starts to work part-time, the number of days of sickness absence is adjusted by the percentage of work. The frequency of sickness absence is defined as the number of incident episodes of sickness absence in a year, divided by the mean number of person-years in that year.

On the individual level, the recurrence density (RD) of sickness absence due to CMDs was computed by dividing the number of employees with recurrent episodes of sickness absence due to CMDs by the person-years of those with a previous episode of sickness absence due to CMDs. Employees with more than one recurrence were counted once in the nominator. The person-years at risk for RD were based on the total time of employment in the observation period after an earlier episode of sickness absence due to CMDs.

A recurrence is defined as the start of a new episode of sickness absence due to CMDs after a recovery period of at least 28 days. The 28-day interval was chosen, because in the Netherlands episodes of sickness absence with an interval of less than 28 days between them are regarded as one episode. The person-years were counted from the moment of the first absence episode due to CMDs until the end of employment, or the end of the observation period, or 1 year of sickness absence, depending on which came first. The person-years had a cutoff point after 1 year of sickness absence (irrespective of diagnosis), because an employee 
was granted a disability pension after 1 year of work incapacity in the Netherlands. Absence episodes were not subtracted from the person-years at risk, with the exception of absence longer than 1 year.

Figure 1 shows the periods at risk for recurrence in different situations. In situation (a) there is one episode of CMD and no recurrent episode. The person-years are counted from the beginning of the first episode of sickness absence due to CMDs until the end of the employment period. In situation (b) a second absence due to CMD occurs $>28$ days after return to work. We define this situation as recurrent sickness absence due to CMD. As in situation a, the person-years are counted from the beginning of the first episode of sickness absence due to CMDs until the end of the employment period. In situation (c) there is a second episode of absence due to CMDs within 28 days after return to work, which is not counted as a recurrence. In the example, the employee is employed during the entire period. In situation (d) there is an episode of sickness absence due to CMDs lasting more than 1 year. The person-years are counted until 1 year of sickness absence.

The RD of sickness absence due to CMDs in the diagnostic categories was calculated by dividing the number of employees with recurrent sickness absence due to CMDs by the person-years at risk in the diagnosis-specific subpopulations, irrespective of the duration of the episodes.

For example: the RD of recurrent sickness absence due to CMDs was assessed in the subpopulation of employees with a previous episode of sickness absence due to adjustment disorders. We distinguished between recurrent sickness absence due to the same type of mental disorder (adjustment disorder in the example) and recurrent sickness absence due to other types of mental disorders.

\section{Determinants}

Gender, age ( $<35,35-44,45-54$ and $\geq 55$ years), marital status (married/not married), duration of employment (04 years, 5-9 years, 10-14 years, 15-19 years and $\geq 20$ years), type of employment (full-time/part-time) and company (Post/Telecommunication) were included as determinants. In 2001, the gross monthly salary scales $(1-2,3,4-5,6-7, \geq 8)$ in the Post and Telecommunication companies ranged from EUR 1,656 (scale 2), 1,813 (scale 3), 2,029 (scale 5), 2,395 (scale 7) to EUR 2,675 (scale 8).

a
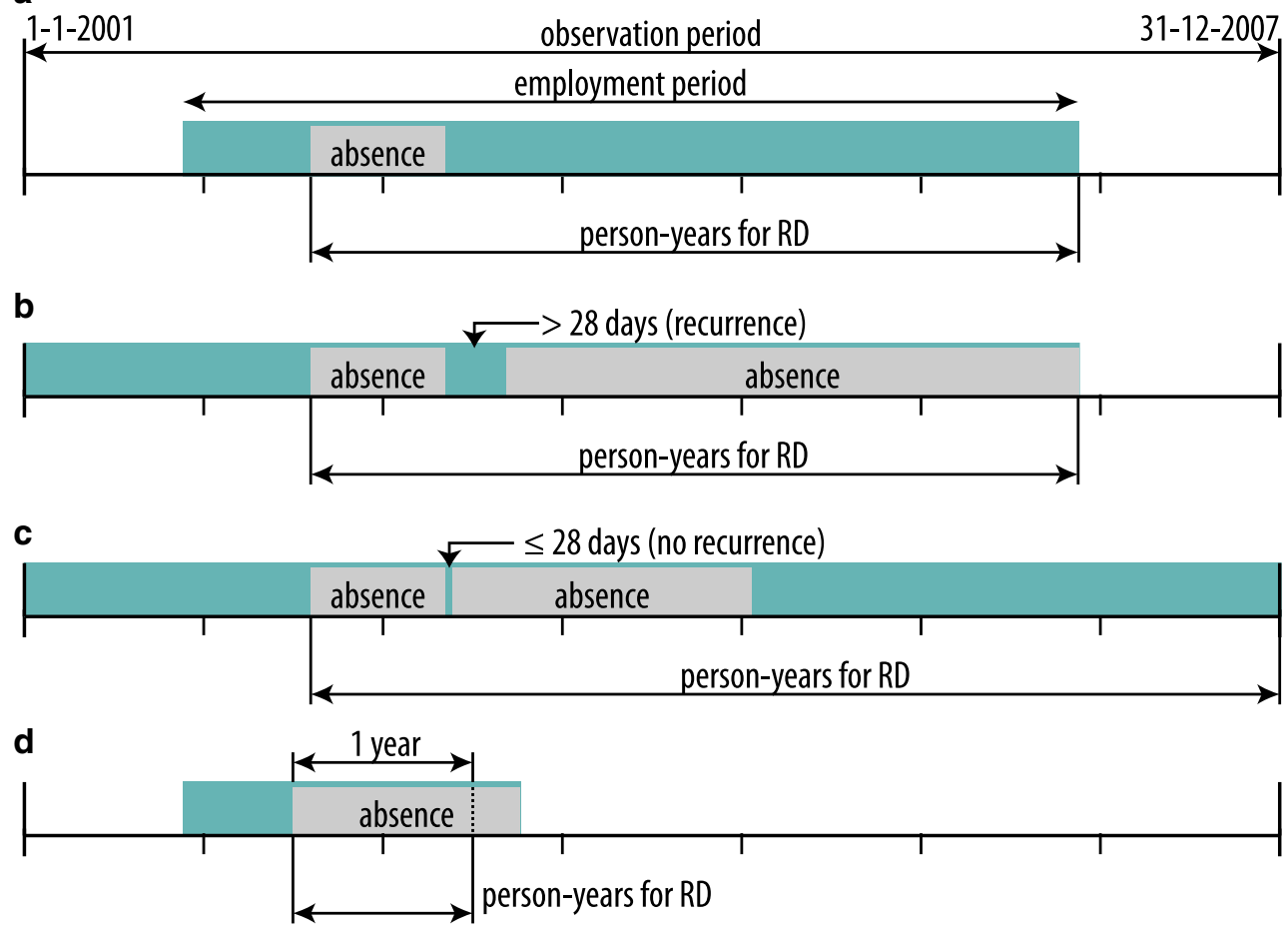

absence $=$ absence due to CMD (Common Mental Disorder)

$\mathrm{RD}=$ Recurrence Density

Fig. 1 Calculation of recurrence density of sickness absence due to common mental disorders 
Statistical analysis

The duration and time-to-onset of recurrent sickness absence due to CMDs was computed in months using Kaplan-Meier survival analysis. Kaplan-Meier survival analysis allows estimation of duration times and comparison of duration times between groups, even when employees are studied for different lengths of time.

We define a rate as the sum of persons with recurrent sickness absence due to CMDs (same or other mental disorder) per unit exposure time. Not all employees are observed for the same length of time. We model counts per unit exposure time, and in our analysis person-years are handled as exposure time. We performed a log-rate analysis with this rate as dependent variable, and initial diagnosis, age, full-time/part-time, marital status, salary scale, employment characteristics and company as explaining variables. The results are presented as rate ratios (RR) with $95 \%$ confidence intervals (CI). In order to examine the influence of determinants, we calculate the rate ratio. A rate ratio is the rate in one group divided by the rate in another group. A rate ratio $>1$ means that group one has a larger rate than group two; if the opposite is true, the rate ratio will be $<1$. All analyses were performed in SPSS for Windows version 15.

\section{Results}

Both the percentage and the frequency of sickness absence decreased in the study population from 2001 to 2007, as is shown in Table 1 . The organizational absence percentages were higher than the national statistics (Statistics Netherlands 2009). Approximately 23 to $25 \%$ of the total percentage of sickness absence is caused by long-term absence due to CMDs in the Telecommunication companies and 9 to $13 \%$ in the Post companies. There was a decreasing trend in long-term (i.e., $>6$ consecutive weeks) sickness absence due to CMDs.

A total of 9,904 employees (7.2\% of the dynamic population) were absent in the period from 2001 to 2007, due to a medically certified CMD, with a total of 12,404 episodes of sickness absence due to CMDs (on average 1.3 episodes per employee).

The duration of episodes of sickness absence due to CMDs is shown in Table 2. Overall, the median duration of a sickness absence episode was 62 days; women had a longer duration of sickness absence (median 68 days; $95 \%$ $\mathrm{CI}=65-71$ days) than men (median 57 days; $95 \% \mathrm{CI}=$ 55-59 days).

Of the 9,904 employees with an episode of sickness absence due to CMDs, 1,925 (19\%) had a recurrent sick-

Table 1 Sickness absence characteristics of the study population

\begin{tabular}{|c|c|c|c|c|c|c|c|}
\hline & \multicolumn{2}{|c|}{ Person-years } & \multicolumn{2}{|c|}{ Absence percentage $(\%)$} & \multicolumn{2}{|c|}{ Absence frequency } & \multirow{2}{*}{$\begin{array}{l}\text { National } \\
\text { statistics }^{\mathrm{b}}(\%)\end{array}$} \\
\hline & Telecom $^{\mathrm{a}}$ & Post & Telecom $^{\mathrm{a}}$ & Post & Telecom & Post & \\
\hline 2001 & 34,749 & 41,467 & 6.5 & 6.3 & 1.51 & 1.34 & 5.4 \\
\hline 2002 & 23,374 & 44,406 & 5.8 & 5.4 & 1.31 & 1.28 & 5.4 \\
\hline 2003 & 19,629 & 46,166 & 4.8 & 4.9 & 1.30 & 1.25 & 4.8 \\
\hline 2004 & 19,091 & 44,221 & 4.3 & 4.6 & 1.22 & 1.20 & 4.3 \\
\hline 2005 & - & 41,077 & - & 4.6 & - & 1.21 & 4.3 \\
\hline 2006 & - & 38,223 & - & 4.3 & - & 1.17 & 4.4 \\
\hline 2007 & - & 36,752 & - & 4.3 & - & 1.18 & 4.4 \\
\hline
\end{tabular}

a The Telecom company left our occupational health services in 2005

b From 2002, the data-collection method changed several times. Public sector not included until 2004

Table 2 Characteristics of sickness absence episodes due to common mental disorders

\begin{tabular}{|c|c|c|c|c|c|}
\hline Type of disorder & Number of episodes & $\%$ & $\begin{array}{l}\text { Median duration days } \\
(95 \% \mathrm{CI}) \\
\text { Total }\end{array}$ & $\begin{array}{l}\text { Median duration } \\
(95 \% \mathrm{CI}) \\
\text { Men }\end{array}$ & $\begin{array}{l}\text { Median duration } \\
(95 \% \mathrm{CI}) \\
\text { Women }\end{array}$ \\
\hline Distress symptoms & 4,243 & 34 & $35(33-37)$ & $33(31-35)$ & $40(37-43)$ \\
\hline Adjustment disorder & 5,202 & 42 & $72(69-75)$ & $69(65-73)$ & $77(71-83)$ \\
\hline Depressive symptoms & 1,019 & 8 & $168(157-179)$ & $165(148-182)$ & $175(155-195)$ \\
\hline Anxiety symptoms & 426 & 3 & $181(152-210)$ & $182(146-218)$ & $181(132-230)$ \\
\hline Other psychiatric disorders & 1,514 & 12 & $75(68-82)$ & $74(64-84)$ & $76(65-87)$ \\
\hline Total & 12,404 & 100 & $62(60-64)$ & $57(55-59)$ & $68(65-71)$ \\
\hline
\end{tabular}


Table 3 Duration in months until recurrence in the employees with a recurrence after an episode of sickness absence due to a common mental disorder

\begin{tabular}{lrl}
\hline Initial episode & $N$ & Median (95\% CI) \\
\hline Distress symptoms & 657 & $11(10-12)$ \\
Adjustment disorder & 779 & $11(9-12)$ \\
Depressive symptoms & 174 & $10(7-12)$ \\
Anxiety symptoms & 62 & $10(7-14)$ \\
Other psychiatric disorders & 253 & $8(6-9)$ \\
Total & 1,925 & $10(10-11)$ \\
\hline
\end{tabular}

ness absence due to CMDs. The median duration until a recurrence of sickness absence due to CMDs in the employees with a recurrence is presented in Table 3. Of those with a recurrence $90 \%$ had the recurrence within 3 years.

Table 4 shows recurrent sickness absence due to CMDs in the cohort with an episode of sickness absence episode due to CMDs. The RD of sickness absence due to CMDs was 84.5 per 1,000 person-years. We distinguished recurrent sickness absence due to the same CMD and recurrent absence due to other CMDs. Because both could apply to the same employee, the total recurrence is not equal to the sum of recurrence due to the same disorder and recurrence due to other disorders.

Sickness absence due depressive symptoms had the highest risk of recurrence. The RD of sickness absence due to distress symptoms, adjustment disorders and anxiety was also high.

\section{Determinants of recurrent sickness absence due to CMDs}

The RD among men was almost as high as among women: 82.7 (95 CI $=77.9-87.5$ ) per 1,000 person-years in men and $87.3(95 \% \mathrm{CI}=81.2-93.4)$ per 1,000 person-years in women.

The recurrence risk for men did not differ from the recurrence risk for women, after adjustment for type of mental disorder, age, salary scale, full-time or part-time work, tenure and company. In order to assess effect modification by gender, we stratified the multivariate analysis according to gender (Table 5). In men, depressive symptoms were related to higher recurrence of sickness absence due to CMDs than distress symptoms and adjustment disorders. In women, no difference by diagnostic category was found. Men between 45 and 55 years of age and women under 45 had a higher risk of recurrent sickness absence due to CMDs than those in the age group of $\geq 55$ years. Men and women with a lower salary had a higher risk of recurrent sickness absence due to CMDs than those with a higher salary, after adjustment for all other variables. Married women had a higher risk of recurrent sickness absence due to CMDs than unmarried women. We found no difference in the risk according to marital status in men. Women with a duration of employment $<5$ years had a higher risk of recurrence than women with a duration of employment of $\geq 20$ years. Employees in the Telecommunication companies had a higher risk of recurrence than employees in the Post companies.

\section{Discussion}

The burden of common mental disorders (CMDs) in the working population is high, not only because of the high prevalence of sickness absence due to CMDs, but also because of the high risk of recurrent sickness absence due to CMDs. The RD of sickness absence due to CMDs was 84.5 per 1,000 person-years. Recurrences occurred within 8-11 months (95\% CI 6-14 months), depending on the initial diagnosis. In $90 \%$ of employees who had a recurrence, the recurrence occurred within 3 years.

The question is whether the results are transferable to other working conditions. The volume and length of follow-up period are as such that the relationships found are likely to be consistent. In this population, a large variation exists in mentally and physically strenuous jobs, which also gives an indication for reproducibility in other populations. We found clear relationships with age, gender and salary

Table 4 Recurrence density (95\% Confidence Interval) of sickness absence due to CMDs, stratified according to initial diagnosis

\begin{tabular}{lrrlll}
\hline Initial episode disorder & $N$ & $\begin{array}{l}\text { Years } \\
\text { at risk }\end{array}$ & $\begin{array}{l}\text { Recurrent CMD } \\
\text { sickness absence same } \\
\text { mental disorder }\end{array}$ & $\begin{array}{l}\text { Recurrent CMD } \\
\text { sickness absence other } \\
\text { mental disorder }\end{array}$ & $\begin{array}{l}\text { Recurrent CMD } \\
\text { sickness absence } \\
\text { total }\end{array}$ \\
\hline Distress symptoms & 3,448 & 8,269 & $44.0(39.5-48.5)$ & $48.0(43.3-52.7)$ & $79.5(73.4-85.5)$ \\
Adjustment disorder & 4,228 & 9,267 & $49.7(45.2-54.3)$ & $45.0(40.7-49.3)$ & $84.1(78.2-90.0)$ \\
Depressive symptoms & 751 & 1,833 & $43.6(34.1-53.2)$ & $68.7(56.7-80.7)$ & $94.9(80.8-109.0)$ \\
Anxiety symptoms & 325 & 765 & $37.9(24.1-51.7)$ & $56.2(39.4-73.0)$ & $81.0(60.9-101.2)$ \\
Other psychiatric disorders & 1,152 & 2,646 & $41.2(33.5-48.9)$ & $67.7(57.7-77.6)$ & $95.6(83.8-107.4)$ \\
Total & 9,904 & 22,779 & $45.8(43.0-48.6)$ & $51.0(48.1-53.9)$ & $84.5(80.7-88.3)$ \\
\hline
\end{tabular}


Table 5 Rate ratios of recurrent sickness absence due to CMDs (same or another mental disorder) a After adjustment for all other variables in the model

\begin{tabular}{|c|c|c|c|c|}
\hline & $N$ & $\begin{array}{l}\text { Men } \\
\text { RR }(95 \% \mathrm{CI})^{\mathrm{a}}\end{array}$ & $N$ & $\begin{array}{l}\text { Women } \\
\text { RR }(95 \% \mathrm{CI})^{\mathrm{a}}\end{array}$ \\
\hline \multicolumn{5}{|l|}{ Initial episode } \\
\hline Distress symptoms & 2,021 & 1.0 & 1,427 & 1.0 \\
\hline Adjustment disorder & 2,508 & $1.03(0.91-1.16)$ & 1,720 & $1.15(0.99-1.33)$ \\
\hline Depressive symptoms & 393 & $1.30(1.07-1.59)$ & 358 & $1.24(0.99-1.54)$ \\
\hline Anxiety symptoms & 184 & $1.00(0.74-1.35)$ & 141 & $1.16(0.81-1.67)$ \\
\hline Other psychiatric disorders & 642 & $1.19(1.00-1.42)$ & 510 & $1.26(1.03-1.53)$ \\
\hline \multicolumn{5}{|l|}{ Age } \\
\hline$<35$ years & 831 & $1.12(0.86-1.47)$ & 1,134 & $1.72(1.18-2.51)$ \\
\hline $35-44$ years & 1,760 & $1.22(0.99-1.51)$ & 1,656 & $1.61(1.12-2.30)$ \\
\hline $45-54$ years & 2,384 & $1.23(1.02-1.50)$ & 1,078 & $1.39(0.97-2.00)$ \\
\hline$\geq 55$ years & 773 & 1.0 & 288 & 1.0 \\
\hline Unmarried & 1,856 & $0.92(0.82-1.04)$ & 1,839 & $0.82(0.72-0.94)$ \\
\hline Married & 3,470 & 1.0 & 2,004 & 1.0 \\
\hline Salary scale $1-2$ & 565 & $1.39(1.04-1.86)$ & 1,405 & $1.60(1.17-2.19)$ \\
\hline Salary scale 3 & 1,787 & $1.67(1.36-2.05)$ & 546 & $1.91(1.37-2.65)$ \\
\hline Salary scale $4-5$ & 823 & $1.28(1.04-1.58)$ & 701 & $1.29(0.96-1.73)$ \\
\hline Salary scale 6-7 & 1,236 & $1.36(1.12-1.65)$ & 939 & $1.16(0.87-1.53)$ \\
\hline Salary scale $8+$ & 1,245 & 1.0 & 486 & 1.0 \\
\hline Full-time & 4,222 & $1.09(0.93-1.28)$ & 828 & $0.99(0.82-1.19)$ \\
\hline Part-time & 931 & 1.0 & 3,114 & 1.0 \\
\hline \multicolumn{5}{|l|}{ Tenure } \\
\hline$<5$ years & 1,212 & $1.02(0.85-1.23)$ & 1,661 & $1.29(1.01-1.66)$ \\
\hline 5-9 years & 759 & $1.03(0.84-1.25)$ & 810 & $1.03(0.79-1.34)$ \\
\hline $10-14$ years & 510 & $1.10(0.91-1.34)$ & 608 & $0.99(0.77-1.27)$ \\
\hline $15-19$ years & 543 & $0.99(0.82-1.20)$ & 468 & $1.08(0.84-1.41)$ \\
\hline$\geq 20$ years & 2,724 & 1.0 & 609 & 1.0 \\
\hline Telecom & 3,582 & $1.33(1.13-1.57)$ & 2,810 & $1.25(1.02-1.53)$ \\
\hline Post & 2,166 & 1.0 & 1,346 & 1.0 \\
\hline
\end{tabular}

scale, and it is plausible that this pattern will also be found in other populations. On the other hand, the size of the relationships will presumably vary between companies. The fact that we found different recurrence densities in Telecom versus Post companies supports this hypothesis. It is recommended to reproduce this study in companies with different working conditions.

Recurrent sickness absence due to the same mental disorder

Mental disorders have been reported to have a high risk of recurrence (Crown et al. 2002; Yonkers et al. 2003; Robinson and Sahakian 2008; Burcusa and Iacono 2007; Hardeveld et al. 2010), and this was confirmed by our results. Sickness absence due to adjustment disorders and distress symptoms were the most frequently diagnosed recurrent disorders, which makes the social and economic burden of these disorders considerable despite their shorter duration.
Recurrence of major depressive disorder in specialized mental healthcare settings is high $(60 \%$ after 5 years, $67 \%$ after 10 years and $85 \%$ after 15 years) and seems lower in the general population (35\% after 15 years) (Hardeveld et al. 2010). The RD of sickness absence due to anxiety and depressive symptoms was high, amounting to 37.9 and 43.6, respectively, per 1,000 person-years.

Recurrent sickness absence due to other mental disorders

Our results show that sickness absence due to CMDs predisposes to sickness absence due to other mental disorders. After sick leave with depressive symptoms, the RD of sickness absence due to other mental disorders was 68.7 per 1,000 person-years, and after anxiety disorders it was 56.2 per 1,000 person-years. Depression is associated with a high risk of long-term sickness absence and work disability (Bültmann et al. 2006, 2008; Lerner and Henke 2008). Our 
results add that after return to work, the risk of recurrent sickness absence due to CMDs has also increased. After an initial episode of sickness absence due to distress, the RD of recurrent sickness absence due to other mental disorders was 48.0 per 1,000 person-years, and after an initial episode with adjustment disorders, it was 45.0 per 1,000 person-years.

Determinants of recurrent sickness absence due to CMDs

The number of previous episodes and subclinical residual symptoms appears to be the most important predictors of recurrence of major depressive disorder (MDD). Gender, civil status and socioeconomic status seem not related to the recurrence of MDD (Burcusa and Iacono 2007; Hardeveld et al. 2010). We investigated the risk of recurrent sickness absence due to CMDs (same or another mental disorder) by gender, age, marital status and salary scale.

Sickness absence due to CMDs occurred more often in women, and this has been reported earlier (Bijl et al. 2002; Hensing and Wahlstrom 2004). Mueller et al. (1999) reported that women had a higher recurrence of a major depressive disorder than men. It is interesting to note that this gender difference seems to disappear after an initial episode of sickness absence due to CMDs. This finding might be biased by the longer episodes of sickness absence found in women than in men (Blank et al. 2008), but this merits further investigation.

In men, depressive symptoms were related to higher recurrence of sickness absence due to CMDs than distress symptoms and adjustment disorders. Men are found to have shorter episodes of sickness absence due to depressive symptoms than women (Koopmans et al. 2008a). Possibly, men with depressive symptoms take less time than needed to recuperate before they start working again, which makes them more vulnerable to repeated episodes of sickness absence due to CMDs.

The RD of sickness absence due to CMDs decreased with age. This is in line with the finding that the incidence of sickness absence due to CMDs in the general population in the Netherlands is higher in employees aged 18-45 than in older employees (Bijl et al. 2002; Spijker et al. 2002). Younger employees might be less able to cope with stressful life events, compared to older employees (Diehl et al. 1996). However, Nieuwenhuijsen et al. (2006) reported a negative association between recovery from mental disorders in employees over 50 years of age. Another explanation might be that younger employees have a lower threshold for sickness absence (Cant et al. 2001). The decrease in RD of sickness absence due to CMDs with age might be also due to differential loss to follow-up, because of early retirement or a disability pension for older employees. Another reason might be a longer duration of sickness absence due to CMDs or other causes in older employees, as several studies have found a longer duration of sickness absence in older employees (Allebeck and Mastekaasa 2004; Duijts et al. 2007). Also a healthy worker effect might explain the age difference, because employees who have suffered from CMDs are more at risk for disability or termination of employment (Koopmans et al. 2008b).

Married women had a higher risk of recurrence than single women, but this difference was not observed in men. Married women might be more vulnerable for CMDs because they combine their work with household and care tasks (Griffin et al. 2002). Mueller et al. (1999) reported that "never married" was a significant predictor of recurrence of an episode of major depression. Lack of a relationship or social support might be a risk factor for the development of depression, and it is possible that social relationships and social support are more important for women than for men. For women, but not for men, dissatisfaction with private life and low social support from colleagues were predictors of long-lasting episodes of sickness absence due to depression (Godin et al. 2009). The lower rate of recurrence of sickness absence due to CMDs in unmarried women could be caused by the longer duration of absence in this group. However, the median duration of sickness absence due to CMDs was the same for married women as for unmarried women (67 days).

Men and women with a lower salary scale had a higher risk of recurrence of sickness absence due to CMDs than those with a higher salary scale. Salary scales reflect social status, and there is evidence of a socioeconomic gradient in CMDs, with a higher risk in the lowest socioeconomic status group (Muntaner et al. 2004). Our results add that in employees of low socioeconomic status, the risk of recurrent sickness absence due to CMDs is also higher than in employees of high socioeconomic status.

A strength of the present study is that we investigated medically certified diagnoses instead of self-reports from the employees, as in the Norwegian HUNT-study for example Mykletun et al. (2006). However, we had no data on comorbidity, and we did not know whether the diagnoses changed over time. An employee can only be registered with one diagnosis for each episode of sickness absence. This is a common shortcoming in studies of sickness absence registers (Wahlstrom and Alexanderson 2004). Moreover, the validity of psychiatric diagnoses is a subject of ongoing debate. Employees with depressive or anxiety disorders often present somatoform complaints (Escobar et al. 1987; De Waal et al. 2004). As somatization (the presentation of physical symptoms instead of depressive symptoms or anxiety) is insufficiently recognized in primary care (Ormel et al. 1994), we expect that sickness absence due to CMDs in our sample underestimates the actual incidence of CMDs. Sickness certification by the 
occupational physicians was based either on the clinical diagnosis obtained from the treating physician (general practitioner or psychiatrist), or determined according to the occupational health guidelines (Van der Klink and van Dijk 2003). Our results may also be biased when occupational physicians were more aware of mental symptoms in a recurrent sickness absence due to CMDs.

It should be noted that the RD person-years are overestimated, because we used the time from the start of the first episode of sickness absence due to CMD instead of the recovery date, whereas someone who is on sick leave is actually not at risk for recurrent sickness absence. The reason for this is that the start of a sickness absence episode is more reliable, because episodes of sickness absence can end due to several reasons: not only return to work, but also leaving employment, the end of the company's contract with the occupational health service, and changes in the labour-contract.

Overestimation of the person-years at risk may have resulted in an underestimation of the risk of recurrence. The risk of recurrence may also have been underestimated because of the high turnover in the study population, as employees who were absent due to sickness are more likely to resign or to be discharged than those who have never reported sick. Furthermore, the risk of recurrent sickness absence due to depressive symptoms and anxiety may have been underestimated due to the longer duration of sickness absence.

\section{Practical implications}

In accordance with the Dutch guidelines (Van der Klink et al. 2007), we advise relapse prevention consultations for a period of 3 years after return to work. This could provide extra opportunities and time for treatment (e.g. cognitive behavioral treatment) and preventive actions (e.g. the reduction of stressors at the workplace or in private life). Occupational physicians should be trained not only to diagnose CMDs, but also to recognize factors associated with a recurrent course (Blier et al. 2007). Van der Klink et al. (2003) reported that it is possible to influence the recurrence rate of sickness absence due to adjustment disorders. They found that the risk of recurrent sickness absence due to adjustment disorders was $20 \%$ lower in the graded activity intervention group than in the "care as usual" group.

Moreover, it would be interesting to develop a screening strategy for distress, depressive and anxiety symptoms and at-work performance deficits. This would make it possible to detect mental problems in an early subclinical stage and to intervene before they develop into disorders that result in sickness absence (Lerner and Henke 2008). Moreover, we recommend that more longitudinal studies should be carried out to investigate sickness absence due to CMDs, focusing on long-term sickness absence as well as recurrences and multiple episodes of sickness absence.

\section{Conclusion}

The results of our study show that employees who have returned to work after an episode of sickness absence due to CMDs are at increased risk of recurrent sickness absence due to CMDs.

Conflict of Interest The authors declare that they have no conflict of interest.

Open Access This article is distributed under the terms of the Creative Commons Attribution Noncommercial License which permits any noncommercial use, distribution, and reproduction in any medium, provided the original author(s) and source are credited.

\section{References}

Alexanderson K, Norlund A (2004) Chapter 1. Aim, background, key concepts, regulations, and current statistics. Scand J Public Health 32:12-30

Allebeck P, Mastekaasa A (2004) Chapter 5. Risk factors for sick leave-general studies. Scand J Public Health 32:49-108

Bijl RV, de Graaf R, Ravelli A, Smit F, Vollebergh WAM (2002) Gender and age-specific first incidence of DSM-III-R psychiatric disorders in the general population Results from the Netherlands Mental Health Survey and Incidence Study (NEMESIS). Soc Psychiatry Psychiatr Epidemiol 37:372-379

Blank L, Peters J, Pickvance S, Wilford J, MacDonald E (2008) A systematic review of the factors which predict return to work for people suffering episodes of poor mental health. J Occup Rehabil 18:27-34

Blier P, Keller MB, Pollack MH, Thase ME, Zajecka JM, Dunner DL (2007) Preventing recurrent depression: long-term treatment for major depressive disorder. J Clin Psychiatry 68:e6

Bültmann U, Rugulies R, Lund T, Christensen K, Labriola M, Burr H (2006) Depressive symptoms and the risk of long-term sickness absence. Soc Psychiatry Psychiatr Epidemiol 41:875-880

Bültmann U, Christensen KB, Burr H, Lund T, Rugulies R (2008) Severe depressive symptoms as predictor of disability pension: a 10-year follow-up study in Denmark. Eur J Public Health 18:232234

Burcusa SL, Iacono WG (2007) Risk for recurrence in depression. Clin Psychol Rev 27:959-985

Cant R, O'Loughlin K, Legge V (2001) Sick leave-Cushion or entitlement? A study of age cohorts' attitudes and practices in two Australian workplaces. Work 17:39-48

Central Statistical Office of the Netherlands (2009) National statistics on sick leave, frequency, period of absence. Heerlen/Voorburg, The Netherlands. Available via: http://statline.cbs.nl. Accessed 6 January 2009

Crown WH, Finkelstein S, Berndt ER, Ling D, Poret AW, Rush AJ, Russell JM (2002) The impact of treatment-resistant depression on health care utilization and costs. J Clin Psychiatry 63:963-971

De Waal MWM, Arnold IA, Eekhof JAH, Van Hemert AM (2004) Somatoform disorders in general practice: prevalence, functional impairment and comorbidity with anxiety and depressive disorders. Br J Psychiatry 184:470-476 
Diehl M, Coyle N, Labouvie-Vief G (1996) Age and sex differences in strategies of coping and defense across the life span. Psychol Aging 11:127-139

Duijts SFA, Kant IJ, Swaen GMH, van den Brandt PA, Zeegers MPA (2007) A meta-analysis of observational studies identifies predictors of sickness absence. J Clin Epidemiol 60:1105-1115

Eaton WW, Martins SS, Nestadt G, Bienvenu OJ, Clarke D, Alexandre P (2008) The burden of mental disorders. Epidemiol Rev 30:1-14

Escobar JI, Burnam MA, Karno M, Forsythe A, Golding JM (1987) Somatization in the community. Arch Gen Psychiatry 44:713718

Godin I, Kornitzer M, Clumeck N, Linkowski P, Valente F, Kittel F (2009) Gender specificity in the prediction of clinically diagnosed depression: results of a large cohort of Belgian workers. Soc Psychiatry Psychiatr Epidemiol 44:592-600

Griffin JM, Fuhrer R, Stansfeld SA, Marmot M (2002) The importance of low control at work and home on depression and anxiety: do these effects vary by gender and social class? Soc Sci Med 54:783-798

Hardeveld F, Spijker J, De Graaf R, Nolen WA, Beekman AT (2010) Prevalence and predictors of recurrence of major depressive disorder in the adult population. Acta Psychiatr Scand. doi:10.1111/ j.1600-0447.2009.01519.x

Hensing G, Wahlstrom R (2004) Chapter 7. Sickness absence and psychiatric disorders. Scand J Public Health 32:152-180

Hensing G, Brage S, Nygård JF, Sandanger I, Tellnes G (2000) Sickness absence with psychiatric disorders-an increased risk for marginalisation among men? Soc Psychiatry Psychiatr Epidemiol $35: 335-340$

Keller MB (2002) The long-term clinical course of generalized anxiety disorder. J Clin Psychiatry 63:11-16

Koopmans PC, Roelen CA, Groothoff JW (2008a) Sickness absence due to depressive symptoms. Int Arch Occup Environ Health 81:711-719

Koopmans PC, Roelen CA, Groothoff JW (2008b) Frequent and longterm absence as a risk factor for work disability and job termination among employees in the private sector. Occup Environ Med 65:494-499

Laitinen-Krispijn S, Bijl RV (2000) Mental disorders and employee sickness absence: the NEMESIS study. Soc Psychiatry Psychiatr Epidemiol 35:71-77

Lerner D, Henke RM (2008) What does research tell us about depression, job performance, and work productivity? JOEM 50:401-410

Mueller TI, Leon AC, Keller MB, Solomon DA, Endicott J, Coryell W, Warshaw M, Maser JD (1999) Recurrence after recovery from major depressive disorder during 15 years of observational follow-up. Am J Psychiatry 156:1000-1006
Muntaner C, Eaton WW, Miech R, O'Campo P (2004) Socioeconomic position and major mental disorders. Epidemiol Rev 26:53-62

Mykletun A, Overland S, Dahl AA, Krokstad S, Bjerkeset O, Glozier N, Aaro LE, Prince M (2006) A population-based cohort study of the effect of common mental disorders on disability pension awards. Am J Psychiatry 163:1412-1418

Nieuwenhuijsen K, Verbeek JHAM, de Boer AGEM, Blonk RWB, van Dijk FJH (2006) Predicting the duration of sickness absence for patients with common mental disorders in occupational health care. Scand J Work Environ Health 32:67-74

Ormel J, VonKorff M, Ustun TB, Pini S, Korten A, Oldehinkel T (1994) Common mental disorders and disability across cultures. Results from the WHO Collaborative Study on Psychological Problems in General Health Care. JAMA 272:1741-1748

Robinson OJ, Sahakian BJ (2008) Recurrence in major depressive disorder: a neurocognitive perspective. Psychol Med 38:315-318

Shiels C, Gabbay MB, Ford FM (2004) Patient factors associated with duration of certified sickness absence and transition to long-term incapacity. Br J Gen Pract 54:86-91

Spijker J, de Graaf R, Bijl RV, Beekman AJTF, Ormel J, Nolen WA (2002) Duration of major depressive episodes in the general population: results from The Netherlands Mental Health Survey and Incidence Study (NEMESIS). Br J Psychiatry 181:208-213

Vaez M, Rylander G, Nygren A, Asberg M, Alexanderson K (2007) Sickness absence and disability pension in a cohort of employees initially on long-term sick leave due to psychiatric disorders in Sweden. Soc Psychiatry Psychiatr Epidemiol 42:381-388

Van der Klink JJL, van Dijk FJH (2003) Dutch practice guidelines for managing adjustment disorders in occupational and primary health care. Scand J Work Environ Health 29:478-487

Van der Klink JJL, Blonk RWB, Schene AH, van Dijk FJH (2003) Reducing long term sickness absence by an activating intervention in adjustment disorders: a cluster randomised controlled design. Occup Environ Med 60:429-437

Van der Klink JJL, Ausems CMM, Beijderwellen BD, Blonk R, Bruinvels DJ, Dogger J (2007) Occupational health care for employees with psychological complaints. Guidelines for occupational physicians (In Dutch). NVAB (Netherlands Society of Occupational Medicine), Utrecht

Wahlstrom R, Alexanderson K (2004) Chapter 11. Physicians'sicklisting practices. Scand J Public Health 32:222-255

Yonkers KA, Bruce SE, Dyck IR, Keller MB (2003) Chronicity, relapse, and illness-course of panic disorder, social phobia, and generalized anxiety disorder: findings in men and women from 8 years of follow-up. Depress Anxiety 17:173-179 